\title{
Dos glosas de romances castellanos en el ms. 4495 de la Bibliothèque Mazarine de París
}

\author{
Two glosses of Spanish ballads in the Ms. 4495 \\ of the Bibliothèque Mazarine in Paris
}

\author{
Joan Mahiques Climent \\ Groupe d'Anthropologie Historique de l'Occident Médiéval \\ Institut National d'Histoire de l'Art
}

RESUMEN: El ms. 4495 de la Bibliothèque Mazarine reúne la mayor parte de las obras, en catalán y en castellano, de Joan Pujol (floruit 1573-1603). Si las primeras han sido estudiadas y publicadas, la mayoría de las poesías en castellano no solo son inéditas sino que pueden considerarse desconocidas debido a la falta de una descripción que transcriba sus primeros versos. Además de ofrecer los inicios de todas las obras castellanas, estudiamos y editamos las dos únicas piezas que hasta el momento podemos suponer que no compuso Joan Pujol, eso son "Oh batalla carnicera" y "Con muy duro y triste hado", que glosan respectivamente los romances "Oh Belerma, oh Belerma" y "Muerto queda Durandarte".

Palabras clave: Joan Pujol, Josep Tastu, Hernando Colón, pliegos poéticos, glosa, romancero, Durandarte.

ABSTRACT: The Ms. 4495 of the Bibliothèque Mazarine includes most of Joan Pujol's Catalan and Spanish works (1573-1603). His Catalan works have been studied and published, but most of the Spanish poems have not only remained unpublished, but can also be considered unknown, because there has never been a bibliographical description accompanying their starting lines. In this article, we offer the beginning of all these Spanish works, in addition to studying and publishing the only two pieces that we can suppose were not written by Joan Pujol: "Oh batalla carnicera" and "Con muy duro y triste hado", which respectively gloss the ballads "Oh Belerma, oh Belerma" and "Muerto queda Durandarte".

Keywords: Joan Pujol, Josep Tastu, Hernando Colón, "pliegos poéticos", gloss, ballad, Durandarte. 
1. La poesía castellana de JoAn Pujol y el MS. 4495 de la BibliothèQUE MAZARINE

Entre los fondos que pasaron del bibliófilo rosellonés Josep Tastu (17871849) a la Bibliothèque Mazarine de París, donde son custodiados en la actualidad, destaca por su importancia el ms. 4495, acéfalo y ápodo, en el cual se ha copiado la mayor parte de la obra conocida de Joan Pujol, uno de los poetas catalanes más relevantes de la segunda mitad del siglo XVI ${ }^{1}$. Josep Tastu envió al obispo de Astorga Félix Torres Amat una descripción sumaria del contenido del manuscrito y también algunos extractos de las composiciones que juzgó más interesantes para que fueran incorporados a su diccionario bio-bibliográfico (Torres Amat, 1836: 516-521)². El obispo de Astorga centró su atención en la poesía catalana del autor, aunque no dejaba de indicar que en el mismo volumen se habían copiado también algunas obras en castellano, entre las cuales mencionaba explícitamente unas glosas al Pater noster, al Ave Maria, al Credo in Deum y a la Salve Regina, así como un poema en alabanza de san Raimundo de Penyafort y una pieza dramática titulada Viaje del hombre.

El escaso interés que hasta entonces había suscitado la poesía castellana de Joan Pujol no se alteró cuando Massó i Torrents (1917) publicó una breve descripción del mismo manuscrito, que había ingresado en la Bibliothèque Mazarine después de la muerte de Josep Tastu. Aparte de las obras castellanas ya mencionadas en el diccionario de Torres Amat, Massó i Torrents daba noticia de la existencia de una "Inuocation" en el f. 94 y de diversos villancicos castellanos a partir del f. 139, así como de unos versos en esta misma lengua justo antes del f. 177. Además de la descripción de este volumen, cuya datación no puede ser anterior al año $1603^{3}$, Massó i Torrents añadía la noticia de otra fuente antigua de suma importancia, que también había transmitido una buena

\footnotetext{
${ }^{1}$ El legado de Josep Tastu, que en el ámbito de la bibliografía catalana tiene cierta importancia, ha sido descrito por Pagès (1888), Molinier (1899: 327-337) y Massó i Torrents (1902).

${ }^{2}$ El ms. 4521 de la Bibliothèque Mazarine incluye diversas cartas originales de Félix Torres Amat dirigidas al ilustre bibliófilo rosellonés, que dio a conocer Pagès (1888). Aunque estas epístolas no aportan datos significativos relativos a la descripción y los extractos del manuscrito de Joan Pujol, sí que constituyen una prueba del importante papel que Tastu tuvo en la compilación del diccionario de Torres Amat, que reconoce explícitamente dicha deuda: "Al Sr. de Tastú debemos un traslado de la misma historia [= el poema de Pujol sobre Lepanto], como también de otros versos latinos glosados y alusivos á ella, y ademas, de una vision en sueños, donde Pujol introduce á Ausias March haciendo un elogio de Luis Joan Vileta, todo en lengua catalana" (Torres Amat, 1836: 516).

${ }^{3}$ Esta cronología se fundamenta en la información del poema copiado en los ff. 103-106 ${ }^{\mathrm{v}}$, que más adelante, en la descripción que ofreceremos, llevará asignado el núm. 8. Se trata de una poesía en alabanza de san Raimundo de Penyafort, que va precedida de una carta fechada del 3 de julio de 1603 en Plegamans y dirigida al obispo de Barcelona Alonso Coloma. Esto nos permite establecer que el ms. 4495 es posterior a la fecha indicada.
} 
parte de la obra de Joan Pujol. Se trata de un impreso barcelonés que Massó i Torrents, a partir de un ejemplar ápodo de la Biblioteca de Catalunya, databa del año 1574, aunque la fecha que figura en el colofón del único ejemplar completo que conocemos es $1573^{4}$.

Después de las aportaciones bibliográficas de Torres Amat y de Massó i Torrents, son contadísimos los estudios que añaden nuevos datos sobre el contenido del ms. $4495^{5}$. Si este manuscrito fue utilizado por Karl-Heinz Anton como base para la edición de las obras catalanas de Joan Pujol (1970), las piezas castellanas en buena parte han permanecido relegadas al grupo de los inéditos, e incluso nos atreveríamos a añadir que hasta el momento se ha ignorado la existencia de algunas de ellas debido a la falta de una descripción que transcriba sus primeros versos ${ }^{6}$. Con el fin de subsanar esta carencia, ofrecemos

${ }^{4}$ El mismo estudioso corrige el error de datación en otro trabajo donde se describen tanto la edición de 1573 como el manuscrito de París (Massó i Torrents, 1932: 45-46 y 73-75). La fecha errónea de 1574 se ha reiterado posteriormente, como sucede en la edición de Karl-Heinz Anton (Pujol, 1970: 11). Dicha confusión debe haber sido provocada por una nota manuscrita visible en la portada del ejemplar ápodo de la Biblioteca de Catalunya (signatura: 10-V-22), donde una pluma antigua ha copiado la fecha "1574" en el margen inferior de la portada. Al lado de esta fecha errónea, se ha añadido a lápiz: "1573”. El otro ejemplar, que sí que es completo, pertenece a la Biblioteca Nacional de España (signatura: R/1007), donde se lee claramente el siguiente colofón, en el último folio: "ESTAMPAT EN BARCELO | na en casa de Pedro Malo | Any 1573.”. Por otra parte, la portada del impreso dice: "LA SINGVLAR | Y ADMIRABLE VICTORIA | QVE PER LA GRACIA DE N. S. D. | obtingue el Serennissim Senyor don Iuan Daustria dela | potentissima armada Turquesca. Composta per|Ioan Pujol Preuere de Mataro. | Dirigida al molt Illustre Senyor don Hyeronim de Pinos. | [Escudo con las armas de los Pinós, y la leyenda a derecha e izquierda: 'SONAT IN | AETHERA FRAGOR'] | EN BARCELONA AB PRIVILEGI.”. Hay un facsímil de este ejemplar en Pujol (1971).

${ }^{5}$ Sí que merece la pena señalar que, antes que Massó i Torrents, Amadeu Pagès ya afirmó que el manuscrito era una "copia autografa de les poesies den Joan Pujol" (1912: 104). Antoni Comas reiteró esta misma idea en el estudio que precedía al facsímil del impreso de 1573 (Pujol, 1971: xi), aunque dicha hipótesis ha sido puesta en tela de juicio por Balsalobre (1995: 106): "Sovint s'ha afirmat que es tracta d'un autògraf, però jo no he sabut trobar enlloc la justificació d'aquesta afirmació: aquesta és una altra de les moltes qüestions que caldrà revisar. Encara més: nombrosos detalls fan pensar que es tracta d'una còpia no autògrafa". Nuestra opinión coincide con la de Balsalobre y, además, nos inclinamos a pensar que no todas las composiciones copiadas en el manuscrito son de Joan Pujol. Nosotros mismos hemos publicado una descripción del ms. 4495 en MCEM (2012, ID 1322).

${ }^{6}$ Aunque Anton (Pujol, 1970) considera las variantes de algunos poemas del impreso barcelonés de 1573, no lo hace en todos ellos. Por otra parte, debe advertirse que hay tres obras catalanas de Joan Pujol que no transmite el ms. 4495 y que tampoco aparecen en esta edición. Nos referimos a "Respira en mi, oh sempiterna guia" (impreso en el f. 88 de la edición de 1573) más dos obras copiadas en una carta manuscrita de Joan Pujol, que comienzan "Com qui forçat se'n va lluny de sa terra" y "L'any 1500 lo calendari canta". En relación al primero de los dos poemas, véase Vellvehí i Altamira (1993). La carta donde se insertan estas composiciones, fechada del día 20 de noviembre de 1585 y dirigida a los canónigos Gabriel Reixac y Jaume Solà, ha sido modernamente editada por un anónimo (Pujol, 1962) que la encontró en la Biblioteca-Arxiu Episcopal de Vic, aunque nosotros no hemos logrado localizar su topográfico. 
a continuación la rúbrica y el íncipit de cada una de las obras castellanas del manuscrito. Estas fueron copiadas una tras de otra en dos grandes secciones que ocupan los ff. $94-149^{\mathrm{v}}$ y $168^{\mathrm{v}}-177$, donde solo encontramos una pieza en otra lengua, más concretamente unos dísticos latinos en honor a san Dionisio Areopagita, que en el siguiente listado clasificamos bajo el núm. 22. Nos hemos limitado a transcribir paleográficamente las rúbricas e inicios de las diferentes composiciones, asignando un número a cada caso e indicando su foliación, resolviendo las abreviaturas en cursiva, y marcando los saltos de línea y saltos entre recto y verso con una barra y con dos barras respectivamente:

1 [F. 94 $4^{r-v}$ Inuocation | [inc.] Dios immenso padre, quen el summo choro | reynas con el hijo, y el spiritu sancto.

2 [Ff. $94^{\mathrm{v}}-95^{\mathrm{v}}$ ] Pater noster: | [inc.] Pater noster muy amado | qui es in celis ruego te.

3 [Ff. 95 $-96^{v}$ ] Aue maria | [inc.] Aue que bolaste al cielo | con tus alas de humildad.

4 [Ff. 96 $-98^{v}$ ] Crede in Deum | [inc.] Credo in deum con toda firmesa | patrem omnipotentem en todo senyor.

5 [Ff. 98 $-99^{\mathrm{v}}$ ] Salue Regina. | [inc.] Salue regina, que con gran vittoria | en el summo cielo, reynas coronada.

6 [Ff. 100-102] Canto en loor y deffension de nuestra | señora de como no fue concebida en | peccado original con autoridad de fi | guras y autores catholicos y aprouados | [inc.] Virgen siem [sic] siempre'ntera, a quien des del cielo | embiado fue, el sancto rescate.

7 [F. 102 $2^{\mathrm{r}-\mathrm{v}}$ ] [inc.] En tanto que christo, en cruz padescia | la mas dura muerte, que nunca se vio.

8 [Ff. 103-106 ${ }^{\mathrm{v}}$ ] Al Jll ${ }^{\text {mo }}$ y $\mathrm{R}^{\mathrm{mo}}$ señor Don Alonço colo | ma obispo Dinissimo de barcelona etc. | Johan pujol | [inc. dedicatoria] Bien creo que V. J. S. haura visto muchas | trobas hechas en alabança de nuestro cata | lan el gloriosa [sic] san raymundo de peña | fort, y tambien soy muy cierto que de [...] $\|^{v}$ [rúbrica] Jntroduction [inc. texto] Mi musa no deue, ni osa mostrarse | yo lo veo bien, por ser mal polida.

9 [Ff. 106 ${ }^{\mathrm{v}}$-139] Historia lamada viaje del hombre en | la qual se introdusen los interlocuto | res siguientes | Hombre $\left.\right|^{\text {va }}$ Entendimiento | Apetito Sathanas | Lucifer | Belzebu | Astarot | Memoria | Volundad [sic] |vb Gula Concupiscentia | Desonestidad | Contento biuo | Jnspiration | Penitentia Confession | Angel || [rúbrica] Al lettor | [inc.] El que mucho quiere, el nombre encubierto | leyendo sus versos, saber del autor.

10 [F. 139-v ] [inc.] Feros sin consuelo, y sañuda dama | remedia el trabajo, anadie creible.

11 [Ff. 139v-141] [inc.] Vos sola soys, maria vos | Dichosa madre del hijo de Dios.

12 [Ff. 141-142 ] Otra | [inc.] De do viene tanto amor | Dios eterno sublimado.

13 [Ff. 142 -143] Otra | [inc.] Ay mi Dios que grande amor | que siendo te tan ingrato.

14 [Ff. 143는 144] Otra | [inc.] Carillo quan ledo stas | estoy lo porques nascido. 
15 [F. 144 ${ }^{\mathrm{r}-\mathrm{v}}$ ] Otra | [inc.] Di me ques esto zagal | como vas regozijado? 16 [Ff. $144^{\mathrm{v}}-145^{\mathrm{v}}$ ] Otra | [inc.] Nueuas traygo de alegria | nueuas milagrosas son.

17 [Ff. $145^{\mathrm{v}}-146^{\mathrm{v}}$ ] Otra | [inc.] Mala noche haueys de hauer | don hijo dundrajo.

18 [Ff. 146'-148] Otra: | [inc.] Vos soys descanço y bien de nos | virgen maria.

19 [Ff. 148-149v] Otra: | [inc.] Tres reyes buscan vn niño | vienen por le adorar. $* * *$

20 [Ff. $168^{\mathrm{v}}-173^{\mathrm{v}}$ ] Glosa del romance, o Belerma: $\|^{\mathrm{v}}$ [inc.] O batalla carnicera tan cruel de cada parte.

21 [Ff. 173는 175] Glosa del Romance, Muerto queda | [inc.] Con muy duro y triste hado | bien que no sin gran vengança.

22 [F. 175 $]$ In laudem $s^{\text {ti }}$. Dionisij Areopagite | Distichon | [inc.] In cruce cum ferret, nostra pius crimina christus | Extremaque dies, instaret vite sue. 23 [Ff. 176-177] [inc.] Yo soy embiado, illustres señores | a rogar hos mucho, por nuestro autor.

Hasta el momento han permanecido inéditas todas estas obras con excepción de los núms. 2 y 3, impresos en los ff. 99-101 [sic $=98^{\mathrm{v}}-101$ ] de la edición barcelonesa de 1573. Podríamos decir que la sucesión de las diferentes composiciones del manuscrito de París responde a un criterio de afinidad. Al núm. 1, de carácter introductorio, siguen cuatro glosas de plegarias latinas (núms. 2-5), mientras que los núms. 6-8 pertenecen al ámbito de la devoción. Bajo el núm. 9 tenemos el Viaje del hombre, que entraría en el género del teatro religioso de carácter alegórico. Por otra parte, el núm. 10 es un elogio dirigido a diferentes damas donde se prodiga el uso de acrósticos y otros recursos retóricos similares. La primera sección de composiciones contiguas finaliza con un grupo de villancicos o canciones con refrán que abarca los núms. 11-19. Algunas de las piezas son contrafacta poético-musicales, como es el caso del núm. 18, que retoma un modelo preexistente cuyas versiones han sido estudiadas por Romeu i Figueras (1974: 233-262; 1999: 136-150)7. A la luz de los poemas que estamos analizando, también se puede destacar la estrecha relación que existe entre las poesías castellana y catalana de Joan Pujol, una relación que es especialmente visible en unas pocas piezas castellanas que no son más que traducciones o adaptaciones de composiciones catalanas preexistentes. Así sucede en el núm. 6, que se correspondería al poema "A vós qui creàreu ab gran providència" (Pujol, 1970: 95-97). Entre los ff. $168^{\mathrm{v}}-177$ del ms. 4495, coincidiendo con el segundo bloque de composiciones copiadas de manera sucesiva, encontramos tres obras en castellano, la última de las cuales, identificada bajo el núm. 23, se asemeja

${ }^{7}$ Josep Romeu estudia y edita diferentes versiones de "Bella, de vós só amorós" y también señala la existencia de algunas contrahechuras del mismo modelo, como es el poema de Onofre Almudèver iniciado "Vos sois descanso y bien de nos". Aunque esta última composición tenga el mismo inicio que la del ms. 4495, se trata de dos obras distintas. 
sobremanera al "Prologo y argumento" (inc.: "Illustres hermanos, y nobles señores") que ocupa los ff. $107^{\mathrm{v}}-108^{\mathrm{v}}$ del Viaje del hombre (núm. 9). Hemos dejado para el final los núms. 20-21, dos glosas de romances sobre la muerte de Durandarte, que antes de expirar pide a su primo Montesinos que le saque el corazón y se lo entregue a la ingrata Belerma. Se trata de una de las múltiples narraciones asociadas a la batalla Roncesvalles. A partir de ahora nos centraremos precisamente en los núms. 20-21 y en los dos romances que glosan, es decir, "Oh Belerma, oh Belerma" y "Muerto queda Durandarte".

\section{GLOSAS DEL CIClO DE DURANDARTE: TRADICIÓN LITERARIA Y TRANSMISIÓN TEXTUAL}

Uno de los pasajes de la Chanson de Roland nos presenta al protagonista justo antes de morir, intentado quebrar su valiosa espada, cuyo nombre es Durendal; pero el acero no se quiebra, a pesar de los continuos golpes con los que es castigado. Entonces Roldán habla a su espada como si esta se tratase de un compañero de batalla: "E, Durendal, bone, si mare fustes! | Quant jo mei perd, de vos nen ai mais cure" (Riquer, 2003: 236). Tal como indica el mismo estudioso, "alguien, en Castilla, no entendió la prosopopeya, y así nació un caballero francés llamado Durandarte, que habría luchado al lado de Roldán en Roncesvalles y alcanzó tal popularidad que aparece en el episodio de la cueva de Montesinos de la segunda parte del Quijote" (Riquer, 2003: 236-237). Es concretamente en los cap. XXII-XXIII donde se narra la onírica aventura donde don Quijote contempla el cuerpo yacente de Durandarte. Montesinos desvela el sentido de esta maravillosa visión al mismo tiempo que recuerda las emocionantes escenas de la muerte de su primo (Cervantes, 1998: I, 820-821)':

En este episodio cervantino se reelaboran, según indica Alonso Asenjo (2000: 53-54), pasajes de los romances "Oh Belerma, oh Belerma", "Muerto queda Durandarte" y "Por el rastro de la sangre" 10 . No cabe duda de que los tres eran muy conocidos y precisamente por eso los retomó Cervantes en clave

\footnotetext{
${ }^{8}$ Adviértase que el primer verso de este último romance tiene una importante variante en la mayor parte de los testimonios, que a continuación marcamos en cursiva: "Muerto yace Durandarte".

${ }^{9}$ Algunos trabajos centrados en las relaciones entre el Quijote y el romancero, como los de Alonso Asenjo (2000), Chevalier (1990) y Gornall y Smith (1985), abordan el episodio de la cueva de Montesinos desde este punto de vista. Este pasaje y su relación con la tradición literaria han sido objeto de numerosos estudios, como se deduce claramente de las referencias bibliográficas que aparecen en Cervantes (1998: II, 147-154).

${ }^{10}$ A partir de ahora nos centraremos en los dos primeros romances, que han sido recopilados por Di Stefano (2010: 172-174). Sobre la difusión del tercer romance ("Por el rastro de la sangre”) durante los siglos XVI-XVII, remitimos a Rodríguez-Moñino (1973: 664; 1978: 195-196).
} 
paródica, propiciando de este modo la complicidad entre el autor y el lector de la novela. Entre todos estos romances, "Oh Belerma, oh Belerma" es sin duda el más antiguo y el más documentado a lo largo del siglo XVI. No solamente fue citado en ensaladas y otras obras con inserciones líricas, sino que también fue contrahecho en clave política, religiosa o paródica ${ }^{11}$. Si en los cancioneros impresos del siglo XVI este romance no suele integrarse en una glosa, sucede justo lo contrario en todos los pliegos poéticos de esta centuria conocidos. Piacentini (1990) se ha centrado precisamente en el estudio de las glosas de este romance $\mathrm{y}$, posteriormente, en un trabajo colectivo, las ha editado (Piacentini y Periñán, 2002: 200-219, núms. I-VII). A partir de esta edición, ofrecemos los dos primeros versos de cada una de ellas, señalando el autor al que las fuentes primarias atribuyen cada poema:

PIACENTINI Y PERIÑÁN (2002: 200-219): NÚMS. Y PRIMEROS VERSOS ATRIBUCIONES

I "Con mi mal no soy pagado | según las faltas que he hecho" Bartolomé de Santiago

II "El conde Partinuplés | y el obispo de Çamora"

III "En los tiempos que en la Francia | reinavan los doze Pares" Francisco de Marquina

IV "Oyendo cómo salieron | los doze Pares de Francia"

V "Quando está con la razón | ligado el entendimiento"

Alberto Gómez

VI “Quexoso voy del bivir. | O quexa muy desigual!’

VII "Si tan poco sentimiento | me diesse verme sin ti"

Bernaldim Ribeiro

Joan Fernández de Heredia

En el siglo XVI se estamparon estas composiciones en forma de pliegos sueltos, con la única excepción del núm. VII, que, de todos modos, sí que fue impreso en Las obras de don Ioan Fernández de Heredia, assí temporales como espirituales (Valencia, Joan Mey, 1562) ${ }^{12}$. A las siete glosas editadas por

11 Véanse diferentes testimonios impresos o manuscritos del romance, así como otras obras que lo citan o glosan, en Rodríguez-Moñino (1973: 633); Labrador, DiFranco y López (2003: 287-288) y Cortijo Ocaña (2006: 185-189). Más adelante nos ocuparemos de las glosas de "Oh Belerma, oh Belerma". Ahora advertimos que la obra que comienza "El radiante Vulcano", aunque aparece como glosa en la rúbrica inicial, se limita a citar los dos primeros versos del romance (Rodríguez-Moñino, 1997: 667-669, núm. 846 [=847]; Pliegos-Madrid, 1960: 41-48, núm. CXXXVI). A modo de contrafacta, para acusar a la casa real hispano-borgoñona de la ingratitud hacia sus servidores, fue escrito un romance atribuido por algunos testimonios a Bernardino de Ayala y por otros testimonios a Diego Hurtado de Mendoza (inc.: "Oh Borgoña, oh Borgoña, por mi mal fuiste engendrada"). El Cortesano de Lluís del Milà menciona las figuras de los francos Durandarte y Belerma con el objeto de criticar la francofilia de uno de los interlocutores que participan en la obra, tal como nota Solervicens (1997: 185). Por otra parte, Belerma se transforma en la Naturaleza humana, Durandarte en Cristo y Montesinos en san Juan Bautista, en un romance que comienza así: "Humana naturaleza, | esposa y hermana amada, | treinta y tres años por ti | tuve vida fatigada" (Labrador, DiFranco y López, 2003: 28, 112-114 y 325, núm. 49). En el Autor del sacreficio de Abraham, el bobo contrahace el inicio del romance cuando exclama: "Oh barriga triste, enferma! | por mi mal fuiste enjendrada" (Rouanet, 1901: 12).

12 Según el orden que Piacentini y Periñán atribuyen a las glosas numeradas I-VI, remitimos a los diferentes pliegos sueltos de cada una de ellas, tal como son descritos por Antonio 
Piacentini y Periñán debería añadirse otra cuya existencia se conocía hasta ahora solo por vía indirecta, a través de algunos de los inventarios de volúmenes y obras que mandó realizar Hernando Colón (1488-1539) con el fin de catalogar los fondos de su biblioteca particular. Las referencias al romance glosado de "Oh Belerma, oh Belerma" las encontramos en el Abecedarium ("Belerma romançe glosa sobre el ·12389 - 14466 - 14553", col. 204) y sobre todo en el Suplementum de la Biblioteca Colombina: "Belerma romance con glosa con las coplas del vir. 14553" (f. 6 ${ }^{\text {va }}$ ), "O batalla carnicera tan cruel de cada 12389 O batalla de dolor sagrienta de cada parte 14553 " (f. $\left.30^{\mathrm{vb}}\right)^{13}$. De dichas anotaciones se deduce claramente que Hernando Colón poseyó dos ejemplares diferentes clasificados en la antigua Biblioteca Colombina bajo los núms. 12389 y 14553. Con toda seguridad, no pertenecían a una misma edición, pues cada uno de ellos transmite diferentes inicios del mismo poema. El Suplementum nos indica que el núm. 14553 también incluía las "Coplas del vir" (inc.: "Llamauale la donzella | y dixo el uil"), de cuya información se ha deducido que estas mismas coplas también figuraban en el núm. 12389, aunque esta conjetura solamente se sustenta en la supuesta semejanza entre las dos fuentes perdidas, una semejanza que es tan probable como incierta ${ }^{14}$.

De esta glosa perdida se conserva una copia manuscrita ignorada en todos los estudios bibliográficos anteriores al que ahora emprendemos. Dicho testimonio es precisamente el que hemos descrito bajo el núm. 20 de las obras castellanas del ms. 4495 de la Bibliothèque Mazarine, donde se ha copiado la mayor parte del corpus poético de Joan Pujol. El hecho de que Hernando Colón, muerto en 1539 , poseyese dos ejemplares diferentes con este mismo poema es un dato concluyente para no atribuirlo al poeta catalán, cuya fecha de nacimiento bien probablemente sea el año 1532, y cuya obra se documenta entre 1573 y $1603{ }^{15}$. ¿Pero si “O batalla carnicera” no fue escrito por Joan Pujol,

Rodríguez-Moñino (1997: 470, 697-698, 346-348, 276-277, 440 y 697, núms. 534, 891, 339-340, 222-223, 486bis y 890). En relación al núm. VII, Piacentini y Periñán señalan dos testimonios manuscritos en la Biblioteca Nacional de España (mss. 2621 y 5593), a los cuales debería añadirse no solamente el testimonio impreso sino también otra copia en los ff. 58-61 del ms. 2050 de la Biblioteca de Catalunya (Fernández de Heredia, 1955: 83-88; Duran, 1998: 298-308).

${ }^{13}$ Hemos consultado estas referencias a través de una edición facsímil del manuscrito, custodiado actualmente en la Biblioteca Colombina de Sevilla (Colón, 1992).

14 Véanse Rodríguez-Moñino (1997: 610, núms. 747 y 747.5) y Askins (1986: 315 y 317, núms. 62 y 82). Sobradamente conocida y documentada es la costumbre de reeditar diferentes pliegos poéticos con el mismo repertorio de obras o incluso con las mismas características formales, pero no son menos abundantes los ejemplos de obras editadas en pliegos poéticos diferentes tanto en el formato como en la elección de las composiciones. En el caso que estamos estudiando, adoptamos una posición sumamente cauta debido a la ausencia de información del Suplementum y al hecho de que el íncipit del poema sea diferente en ambos ejemplares.

15 En relación a la datación de la poesía de Joan Pujol, los límites que hemos establecido se refieren a la publicación de la edición barcelonesa de 1573 y a la fecha de una carta que figura 
entonces no sería lógico pensar que tampoco lo fuese la glosa copiada en los siguientes folios del mismo volumen? Las afinidades que existen entre los núms. 20 y 21 nos inducen a considerarlo así. Ambos casos se disponen en forma de coplas con su glosa, con la misma estructura métrica de diez octosílabos (abbaabcdccd) cuyos dos últimos versos constituyen la cita del romance. Además, "Con muy duro y triste hado" también glosa un conocidísimo romance sobre el mismo tema, eso es "Muerto queda Durandarte", documentado a través de diversos pliegos poéticos, cancioneros impresos y copias manuscritas; y glosado, recreado y citado en ensaladas $\mathrm{u}$ otros poemas con inserciones líricas ${ }^{16}$. A continuación ofrecemos un listado de las glosas quinientistas que de este romance se conocían hasta ahora, con las atribuciones que figuran en las fuentes antiguas:

PIACENTINI Y PERIÑÁN (2002: 184-193): NÚMS. Y PRIMEROS VERSOS

ATRIBUCIONES

I "Por pago de sus dolores | al último fin llegado" Burguillos

II "El más desastrado día | que jamás se vio en la tierra"

III "Quando el gran Carlos quería | sin razón dar en España"

IV "Aunque nuevas de pesar | sea pesar descubrillas"

$\mathrm{V}$ "De mil ansias rodeado | y en fuego d'amor deshecho"

Doctor Villalobos

en la obra núm. 8 de nuestra descripción de las obras castellanas del ms. 4495. A la hora de establecer la fecha de nacimiento de nuestro poeta, nos ha sido de gran utilidad el estudio de Pavia i Simó (1994: 84). Especialmente sugerente es la relación que establece entre el poeta Joan Pujol (cuya obra es copiada en el ms. 4495) y el músico Joan Pau Pujol (1570-1626), ambos naturales de Mataró, pues el primero podría ser el "venerable mn. Joan Pujol" que aparece como padrino en la partida de bautismo del segundo. Si esto es así, entonces el poeta Joan Pujol sería el hermano mayor de Montserrat Pujol, padre del músico Joan Pau Pujol. El hermano mayor de Montserrat Pujol fue bautizado bajo el nombre de Joan Pau Pujol en el año 1532, tal como se deduce de la información que aporta Vellvehí i Altamira (1991: 77). El autor de este último estudio propone una fecha de nacimiento que, siguiendo de cerca la hipótesis de Antoni Comas (Pujol, 1971: ix), se situaría entre los años 1514 y 1516, hipótesis que Balsalobre (1995: 106) considera errónea y que nosotros mismos descartamos al establecer el año 1532 como posible fecha de nacimiento del poeta.

${ }^{16}$ El trabajo más reciente y exhaustivo sobre la difusión de este romance lo debemos a Tato (2010). Además, véanse Rodríguez-Moñino (1997: 156 y 555-556, núms. 29 y 659-660; 1973: 602-603) y Cortijo Ocaña (2006: 185-189), y añádase también el testimonio impreso en un pliego suelto que ocupa los ff. 132-135 de un volumen de la Biblioteca Comunale Augusta de Perugia (signatura: I L 1402): "Cinco Romances. | El primero que dize. Estaua se la condessa. | El segundo que dize. Vamo nos dixo mi tio. | El tercero dize. De Merida sale el Palmero. | El quarto dize. Muerto queda Durandarte. | El quinto que dize. Herido esta don Tristan.”. Diversos romanceros del siglo XVI refunden este romance con "Oh Belerma, oh Belerma", hecho que también se documenta más tarde en la Floresta de Tortajada (Rodríguez-Moñino, 1978: 172). Todo parece indicar que esta versión de la Floresta está en el origen de algunos romances de la tradición oral moderna sobre la muerte de Durandarte, registrados tanto en Andalucía como en Asturias (Catalán, 1998: 1-34; Catarella, 1989: 621). Esta última autora señala, concretamente, la existencia de una versión del romancista Juan José Niño derivada de "la adaptación y revisión que hizo Damián López de Tortajada en la Floresta de varios romances (Valencia, 1652) de unos romances de Durandarte y Belerma publicados por Juan de Timoneda [...] y por Lucas Rodríguez". 
De todas estas glosas, solamente la núm. III nos ha llegado a través de pliegos sueltos del siglo XVI (Rodríguez-Moñino, 1997: 655-656, núms. 659-660). En todo caso, a estas cinco glosas deberá añadirse a partir de ahora la que transmite el ms. 4495 de la Bibliothèque Mazarine. ¿Pero a partir de qué fuente o fuentes las dos glosas de romances se copiaron en el manuscrito de París? Nada podemos afirmar al respecto, pero no descartamos que pueda tratarse de un pliego suelto perdido en la actualidad, quizás el mismo al que el Suplementum de la Biblioteca Colombina asigna el núm. 12389, aunque, según el conocimiento actual de la bibliografía antigua, dicha hipótesis es tan difícil de confirmar como de negar.

Centrémonos en las versiones de los romances tal como son copiados en el manuscrito de París. Salta a la vista que los versos de "Oh Belerma, oh Belerma" tienen en el poema núm. 20 un orden notablemente diferente al de la mayor parte de los testimonios quinientistas del mismo romance. Es verdad que, en relación al texto glosado, el núm. 20 sí que se asemeja a la glosa de Joan Fernández de Heredia que comienza "Si tan poco sentimiento", tal como se desprende de las siguientes transcripciones ${ }^{17}$ :

BIBLIOTÈQUE MAZARINE, MS. 4495, FF. $169-173^{v}$

¡O Belerma, o Belerma, por mi mal fuiste engendrada!, que siete años te serví sin de ti alcançar nada. Ora que bien me querías, muero yo en esta battalla. No me pesa de mi muerte, aunque temprano me lama, mas pésame que de verte y servirte me dexava. Montesinos, Montesinos, una cosa os demandava: después que yo seré muerto y mi alma arrancada, vos levéys mi coraçón adonde Belerma estava.
LAS OBRAS DE DON IOAN FERNÁNDEZ DE HEREDIA, VALENCIA, 1562, FF. 69v $-74^{\mathrm{v}}$

¡O Belerma, o Belerma, por mi mal fuyst'engendrada!

Siete años te serví sin alcançar de ti nada.

Ora que bien me querías, muero yo'n esta batalla. No me pesa de mi muerte, aunque temprano me llama, mas pésame que de verte y de servirte dexava. Montesinos, Montesinos, una cosa os demandava: que, quando yo sea muerto y mi alma sea arrancada, vos llevéys mi coraçón adonde Belerma estava.

${ }^{17}$ El ejemplar consultado de Las obras de don Ioan Fernández de Heredia (Valencia, Joan Mey, 1562) pertenece a la Biblioteca Nacional de España (signatura: R/2874). Hemos establecido las dos versiones del romance a partir de las fuentes primarias, tomando los dos últimos versos de cada copla, sin tener en cuenta ni la edición de "O batalla carnicera" que figura al final del presente artículo ni las ediciones de "Si tan poco sentimiento" (Piacentini y Periñán, 2012: 216 219; Fernández de Heredia, 1955: 83-88). Aplicamos los mismos criterios de edición que indicamos al inicio del apartado siguiente. 
$\mathrm{Y}$ dalde todas mis tierras, las que yo señoreava.

Que, pues que yo a ella pierdo, todo el bien con ella vaya. Y servidla en mi lugar, como de vos s'esperava.

Que tenga de mí memoria una vez en la setmana, y dezidle que se acuerde que tan cara me costava. ¡Soccorredme, Montesinos, que'l coraçón me desmaya, que'l braço tengo cançado y la mano del espada, la vista tengo perdida, mucha sangre derramada, los extremos siento fríos y quitáseme la habla! ¡Ojos que me vieron ir nunca me verán en Francia! Pues que quiere la ventura que nuestro deudo se parta, ¡abráçame, Montesinos, que ya se me salle el alma!
Y dalde todas mis tierras, las que yo señoreava. Y pues a ella perdí, todo el bien con ella vaya. $\mathrm{Y}$ servilda en mi lugar como de vos s'esperava, y traelde a la memoria una vez en la semana, $\mathrm{y}$ dezilde que se acuerde que tan cara me costava. ¡Abraçadme, Montesinos, que'l coraçón me desmaya, el braço traygo cansado y la mano dell espada, la vista tengo perdida, mucha sangre derramada, los estremos tengo fríos y quítaseme la habla! ¡Ojos que me vieron yr nunca me verán en Francia! Pues que quiere la ventura qu'oy nuestro deudo se parta, ¡abraçadme, Montesinos, que a mí sálleseme'll alma!

Joan Fernández de Heredia, muerto en el año 1549, es uno de los autores compilados no solamente en el Cancionero general de Hernando del Castillo, ya desde la edición princeps de 1511, sino también en El cortesano de Lluís del Milà, que se imprimió por primera vez en el año 1561 (Fernández de Heredia, 1955: xi-xix). A partir de estos datos podemos establecer que, a la semejanza que hay entre los dos textos del romance de Belerma, tal como son transmitidos por ambas glosas, debería de añadirse también un marco cronológico común, ya que la copia del manuscrito parisino debe vincularse inequívocamente a la obra impresa en el testimonio perdido que poseyó Hernando Colón, muerto en el año 1539. Todo parece indicar que los textos del romance citados en ambas glosas derivan de antígrafos de la misma familia y muy cercanos, e incluso no podríamos descartar que "Si tan poco sentimiento" partiese directamente del romance tal como aparece en la otra glosa, comenzada "O batalla carnicera" o bien "O batalla de dolor". Después de constatar dichas similitudes, podemos afirmar con toda propiedad que el núm. 20, copiado en el ms. 4495, no puede atribuirse de ningún modo a Joan Pujol.

Muy diferente es el caso del núm. 21 ("Con muy duro y triste hado"), una glosa de "Muerto queda Durandarte" que, como ya hemos indicado, creemos que no fue escrita por el poeta de Mataró, aunque carecemos de pruebas docu- 
mentales que lo demuestren con tanta contundencia como en la glosa anterior. Después de haber cotejado el textos de las diferentes versiones de "Muerto queda Durandarte", hemos llegado a la conclusión de que el testimonio que conocemos más semejante a la versión que transmite el núm. 21 deriva de una glosa compuesta por el doctor Villalobos, cuyo íncipit es "Aunque nuevas de pesar", impresa en el Cancionero general de obras nuevas (Zaragoza, Esteban de Nájera, 1554) ${ }^{18}$. En este caso, el hecho de que la glosa del ms. 4495 contenga dos estrofas más que la glosa del cancionero de 1554 determina que el romance tenga cuatro versos más en la versión manuscrita que en la impresa ${ }^{19}$ :

BIBLIOTĖQUE MAZARINE, MS. 4495, FF. $173^{\mathrm{v}}-175$

Muerto queda Durandarte al pie d'una gran montaña. Con él está Montesinos, que'n su muerte se hallara. Rompiendo l'está los pechos; el coraçón le sacava por levarlo a Belerma, como él se lo rogara.

Después le dio sepultura en tierra deshabitada. Lorando sus tristes ojos, d'esta suerte lamentava: “ Durandarte, Durandarte, Dios perdone la tu alma! ¡A mí saque d'este mundo porque contigo me vaya donde hay plazeres tantos y bien que nunca se acaba!"
CANCIONERO GENERAL DE OBRAS NUEVAS, ZARAGOZA, 1554, FF. CXV ${ }^{\mathrm{V}}$-CXVII

Muerto queda Durandarte al pie d'una gran montaña. Con él queda Montesinos, que a su muerte se hallara. Desarmándole los pechos, el coraçón le sacava para llevallo a Belerma, como él se lo rogara.

Palabras l'está diziendo que la tierra lastimava: “Durandarte, Durandarte, Dios perdone la tu alma, y a mí saque d'este mundo para que contigo vaya!"

${ }^{18}$ La portada de este impreso dice: "CANCIONE- | ro general de obras nue | uas nunca hasta aora impressas. | assi por ell arte Española, $\mid$ como por la Tosca- $\mid$ na. Y esta $\mid$ primera es el Triumpho de la $\mid$ muerte traduzido por do | Iuan de Coloma | [marca de impresor con la leyenda: 'IVSTA | VLTIO'] | Impresso Año. M.D.LIIII.". En el f. cciiiv , el colofón concluye: "Fve impresso | el presente Canezonero, en la muy no- | ble ciudad de Caragoça | en casa de | Steuan G. de Nagera. | Acabóse | el .i. de Mayo. Año de | 1554.”. El único ejemplar conocido pertenece a la Herzog-August Bibliothek de Wolfenbüttel (signatura: A. 196.18.1 Poet.). Esta información la debemos a la edición de Clavería (1993).

${ }^{19}$ Transcribimos el texto del ms. 4495 según los criterios indicados en la nota 17. En relación con la versión del Cancionero general de obras nuevas, no partimos del impreso original de 1554 sino del texto establecido por Clavería (1993: 161-163, núm. LXXVI), al cual hemos introducido algunos cambios relativos a la puntación, al uso de mayúsculas y a la alternancia $u / v$, que nosotros hemos regularizado. Véase otra edición de la misma glosa en Piacentini y Periñán (2002: 192, núm. IV). 
Al ser más breve, la glosa del Cancionero general de obras nuevas difícilmente podría considerarse como la fuente de la que deriva el romance tal como lo transmite el ms. 4495, aunque sí que podemos suponer el proceso inverso, es decir, que el texto del manuscrito de París en realidad sea el testimonio tardío de una obra que ya se había difundido a mediados del siglo XVI y que era conocida por el autor de "Aunque nuevas de pesar". Si pudiésemos demostrar que la versión del romance tal como aparece en el ms. 4495 es más antigua que la que encontramos en el cancionero de Esteban de Nájera, entonces tendríamos un argumento más (aunque no fuese concluyente) para no atribuir "Con muy duro y triste hado" a Joan Pujol. En todo caso, lo que nos parece fuera de dudas es que las glosas del manuscrito de París y del cancionero impreso por Esteban de Nájera tienen un parentesco inequívoco que nos haría remontar a un antígrafo no demasiado lejano que no hemos logrado localizar.

Después de este breve recorrido a través de las glosas quinientistas de los romances sobre la muerte de Durandarte, pasaremos a la edición de las dos obras.

\section{3. “O BATALLA CARNICERA" Y "CON MUY DURO Y TRISTE HADO”: EDICIÓN DE DOS GLOSAS DE ROMANCES}

A continuación editaremos las dos glosas de romances copiadas en los ff. 168v-175 del ms. 4495 de la Bibliothèque Mazarine de París. En lo referente a las normas de transcripción, tal como ya hemos indicado al establecer algunas versiones de los romances, regularizamos las grafías en las alternancias $i / j$ y $u /$ $v$ y eliminamos la $h$ en las palabras hos, thezoro, charo o sus derivados. Marcamos con el apóstrofo algunas elisiones que hoy no tienen representación gráfica, y mantenemos la forma el del artículo femenino delante de las palabras alma y espada. Separamos las palabras, puntuamos, acentuamos y utilizamos mayúsculas y minúsculas según la normativa actual. Aparte de estas únicas excepciones, mantenemos en las soluciones gráficas del original el resto de los casos, incluso en algunas situaciones que están al margen de las convenciones ortográficas vigentes o que delatan una falta de correspondencia entre grafías y fonemas. Así sucede, por ejemplo, cuando $l$ - representa el fonema palatal [•]. También marcamos entre corchetes los fragmentos textuales que añadimos en nuestra edición, y resolvemos las pocas abreviaturas. En un caso, indicamos con salto de línea y puntos suspensivos la laguna de un verso no copiado. Corregimos algunos errores evidentes del amanuense, indicando en nota la lección del manuscrito. Para señalar los dísticos de los romances que se incrustan en las glosas, utilizamos la letra cursiva. En relación a la foliación, nuestra edición omite la numeración, aunque sí que marca con una barra los saltos entre recto y verso: | para el inicio del recto; |v para el inicio del verso. 


\section{[ff. 168v-173v] GLOSA DEL ROMANCE "O BELERMA" |}

¡O batalla carnicera,

tan cruel de cada parte,

nunca yo te conosciera

porque la muerte no viera

de mi primo Durandarte!

Quién le vio en tierra hierma,

leno de tanta lançada,

diziendo con boz enferma:

“ $O$ O Belerma, o Belerma,

por mi mal fuiste engendrada!

Por mi mal, no por mi bien;

pues que fuera de tus braços,

herido con tal vayvén,

sin que sepa yo de quién,

muero, hecho mil pedaços.

$¡ O$ quién supiesse de ti,

en esta triste jornada,

si tienes dolor de mi,

que siete años te serví

sin de ti alcançar nada! |v

¡Más que de locura digo,

o Belerma, qué harás, aunqu'estoy si[n] mí y contigo!

$¡ O$ si fuesse yo el testigo, quando mi muerte sabrás!

Bien que'l fin d'estos mis días por mí honroso se halla

- ¡o dobladas ansias mías!-,

ora que bien me querías

muero yo en esta battalla.

Muero, pero no mi fe;

porque'n la postrera hora,

mientra sentido terné,

contino confessaré

a Belerma por señora.

Pues que mi sangre se vierte

con gloria gran de mi fama

y en mi honra se convierte,

no me pesa de mi muerte,

aunque temprano me lama. |

Pésame porque quisiera,

pues mi fin veo tan cierto, 
que'n tus braços yo muriera

o a lo menos que te viera

— iay, triste! — antes de muerto.

De mi desdichada suerte, lo que más me atormentava... no las heridas de muerte, mas pésame que de verte $y$ servirte me dexava.

Viéndome cuytado, ansí, donde la vida no estimo, ¡qué gran bien es para mí que'n mi muert'estéys aquí, mi señor y mi buen primo!

Pues mis gala[r]dones dinnos la muerte me los quitava, qu'eran fin de mis caminos, Montesinos, Montesinos, una cosa os demandava. |v

Bolved el rostro a mirar, dexad el lorar aparte y procurad d'escuchar esto que os quiere rogar vuestro primo Durandarte. $\mathrm{Y}$ es que sepa yo de cierto esta cosa señalada; vos tengáys este concierto: después que yo seré muerto y mi alma arrancada,

d'este cuerpo malherido (pues que vos claro sabéys quánto a Belerma ha querido), de mucha merced os pido aquella parte le deys do con cierta impressión comigo siempre levava su figura con razón. Vos levéys mi coraçón adonde Belerma estava |

porque vea, viendo a él, la impressión que hizo en vella. Y verá, mirando en él, quán amarga y quán cruel es mi muerte, ausente d'ella. 
siempre d'ella me acordava.

Enterrame en estas sierras

$y$ dalde todas mis tierras,

las que yo señoreava.

Y diréys que si yo fuera del mundo todo señor, pues mi señora era, todo junto se lo diera y más si fuera mayor.

Porque siento qu'es de cuerdo qu'ella mis despojos haya, en esto firmo y acuerdo que, pues que yo a ella pierdo, todo el bien con ella vaya. |v

Y notad bien su meneo.

Mirad el gesto que haze, que mucho saber desseo d'este fin en que me veo si le peno o si le plaze. ¿No veys qué devanear, o fiera muerte y muy brava? Querédmela encomendar y servidla en mi lugar, como de vos s'esperava.

Las justas, torneos, galas que hize con tanta fe, los atavíos y salas, aquellas sospechas malas que de Gayferos hablé, todo esto es gran historia de quando mi vida ufana. Dezilde, porque haya gloria, que tenga de mí memoria una vez en la setmana. |

Aquel que venció los moros del campo qu'ell aplazó, quien gastó bien sus tezoros, quien a Francia causó loros, quien solo ella venció, ella sola es quien le pierde, pues a ella solo amava. Vuest[r]a merced la recuerde y dezidle que se acuerde que tan cara me costava, 
no porque pierdo la vida, pues que me gano en perdella, mas porque no fue perdida do mejor fuera servida y no aquí, tan lexos d'ella.

No son esto desatinos, ni salgo fuera de raya.

¡Ay, que ya pierdo los tinos! ¡Soccorredme, Montesinos, que'l coraçón me desmaya!

Quiéroos, ${ }^{20}$ señor, acordar que, a quantos salieren sanos y bivos d'este lugar, les queráys por mí besar |v a todos juntos las manos.

Dezid, si muero - icuytado!que mi muerte fue vengada en moros que he derribado; que'l braço tengo cançado, y la mano, del espada.

Lo mejor me olvido ya.

O Belerma, mi señora, ¿vuestra merced dónd'está?

¿Cómo no venís acá para soccorrerme agora?

¡Mas ay, ay, que su venida no aprovecharía nada! Leno de tanta herida, la vista tengo perdida, mucha sangre derramada.

Impossible es, si me viesse (tan sangriento y tal estoy), conoscerme, aunque me viesse. Si por la habla no fuesse, no sabría quién yo soy. ¡Ay, mis esfuerços y bríos! Ved mi muerte quál s'entabla. De mi sangre corren ríos, los extremos siento fríos y quítaseme la habla. |

¡Adiós, adiós, don Roldán! ¡Adiós, Urgel y Oliveros,

\footnotetext{
${ }^{20}$ Quiéroos] Quierhos
} 
don Namós y don Beltrán,

Reynaldos de Montalván,

Amón, Dudón, Gayferos!

Los más d'estos vi morir.

Si digo de mi ganancia,

con ellos puedo dezir:

ojos que me vieron ir,

nunca me verán en Francia.

De ti, viejo emperador, me pesa, y de tu desonra, porqu'escojes lo peor:

por Galarón el traidor ${ }^{21}$, hoy pierdes los doze y honra.

De tamaña desventura escrivid vos una carta, después de mi sepultura, pues que quiere la ventura que nuestro deudo se parta.

Y finalmente dezí, quando a Belerma veáys, que no le pese por mí: pues que vos quedáys aquí, que'n mi lugar la sirváys. |v $\mathrm{Y}$, pues que tengo continos tragos de muerte sin calma, que del morir son vezinos, abráçame, Montesinos, que ya se me salle el alma."

[ff. 173v-175] GLOSA DEL ROMANCE "MUERTO QUEDA"

Con muy duro y triste hado, bien que no sin gran vengança en moro[s] que ha derribado y crudamente lagado con espada y con su lança, mostrándose un fiero Marte, sin aprovecharle maña ni destresa, fuerça ni arte, muerto queda Durandarte al pie d'una gran montaña.

Allá cerca Roncesvalles, murió por su desventura.

21 traidor] trandor 
En desabitados valles

donde no hay plaças ni calles,

fue su triste sepultura;

donde, lexos de vezinos,

perdiendo su vida cara

con dolorosos destinos, |

con $^{22}$ él está Montesinos,

que'n su muerte se hallara.

En su muerte se halló

— ¡ay, qué desdichada suerte!-

y en sus braços espiró,

en el punto que finó,

con arrebatada muerte.

$\mathrm{Y}$ viendo sus miembros deshechos,

pues remedio no hallava,

...

rompiendo l'está los pechos;

el coraçón le sacava.

Leno de gran confusión,

según que pienso y estimo,

le sacó el coraçón

por cumplir con gran razón

el mandado de su primo.

$Y$ con triste mente'nferma,

en vaso de oro l'echava,

triste y solo en tierra yerma,

por $^{23}$ levarlo a Belerma

como él se lo rogara.

Luego que se lo sacó,

todo embuelto en triste loro,

a Durandarte miró

y en sus braços lo tomó

diziendo: “¡Ay, mi tezoro!” |v

$\mathrm{Y}$ assí, leno de tristura

con razón en tal jornada,

baxó d'una peña dura;

después le dio sepultura

en tierra deshabitada.

Partió luego su camino, levando la triste nueva, maldiziendo de contino su doloroso destino

\footnotetext{
${ }^{22}$ con] $\mathrm{C}$ con

${ }^{23}$ por] $\mathrm{P}$ por
} 
con el gran pesar que lieva.

Y embuelto en mil enojos, con el dolor rebentava como quien va por abrojos.

Lorando sus tristes ojos, d'esta suerte lamentava:

“AAy, mi primo, dónd'está tu beldad tan escogida? ¿Ay, triste, qué sentirá, quando tu muerte sabrá, tu Belerma tan querida? ¡Ay de mí, que'n esta parte hallé pesares sin calma! ¡Mejor fuera no hallarte! iDurandarte, Durandarte, Dios perdone la tu alma! |

Dios perdone la tu alma, porque dexes con vittoria de tus pecados la salma $y$, con sempiterna palma, bivas en su sancta gloria. $\mathrm{Y}$ pues tanto me confundo con pesar que me desmaya, $\mathrm{y}$ en querer morir me fundo, a mí saque d'este mundo porque contigo me vaya.

Contigo me vaya luego, dexando la triste vida, pues con tal desasossiego como quien arde'n un fuego la tengo aborrescida. Que, con tan duros quebrantos, el bivir se menoscaba. Liéveme Dios a sus sanctos, donde hay plazeres tantos y bien que nunca se acaba." |v

\section{BIBLIOGRAFÍA}

Alonso Asenjo, Julio (2000): "Quijote y romances. Uso y funciones”, en Rafael Beltrán (ed.), Historia, reescritura y pervivencia del romancero: estudios en memoria de Amelia GarcíaValdecasas, Valencia, Publicacions de la Universitat de València, pp. 25-65.

Askins, Arthur L-F. (1986): "The Pliegos Sueltos of the Biblioteca Colombina in the Sixteenth Century: Notes to an Inventory", Romance Philology, XXXIX/3, pp. 305-322. 
Balsalobre, Pep (1995): “Joan Pujol: una lectura contrareformista d'Ausiàs March”, Estudi general, XIV, pp. 105-135.

Catalán, Diego (1998): Arte poética del romancero oral. Parte $2^{a}$. Memoria, invención, artificio, Madrid, Fundación Ramón Menéndez Pidal-Siglo Veintiuno Editores.

Catarella, Teresa (1989): "Juan José Niño, el más grande romancista gitano-andaluz", en Pedro M. Piñero, Virtudes Atero, Enrique J. Rodríguez Baltanás y María Jesús Ruiz (eds.), El romancero. Tradición y pervivencia a fines del siglo XX. Actas del IV Coloquio Internacional del Romancero (Sevilla - Puerto de Santa María - Cádiz, 23-26 de Junio de 1987), Cádiz, Fundación Machado-Universidad de Cádiz, pp. 617-624.

Cervantes, Miguel de (1998): Don Quijote de la Mancha. Edición del Instituto Cervantes dirigida por Francisco Rico, con la colaboración de Joaquín Forradellas. Estudio preliminar de Fernando Lázaro Carreter, 2 vol., Barcelona, Instituto Cervantes-Crítica.

Chevalier, Maxime (1990): "Cervantes frente a los romances viejos", Voz y letra. Revista de Filología, I/2, pp. 191-196.

Clavería, Carlos (ed.) (1993): Cancionero general de obras nuevas (Zaragoza, 1554). Edición de Carlos Clavería, Barcelona, Edicions Delstre's.

Colón, Hernando (1992): Abecedarium B y Supplementum. Ed. facsímil de los manuscritos conservados en la Biblioteca Colombina de Sevilla, Madrid, Fundación Mapfre América-Cabildo de la Catedral de Sevilla.

Cortijo Ocaña, Antonio (2006): "El amor como burla y parodia erótica en la comedia burlesca áurea. A propósito de El amor más verdadero, Durandarte y Belerma de Guillén Pierres", en José Ignacio Díez y Adrienne L. Martín (eds.), Venus Venerada: tradiciones eróticas de la literatura española, I, Madrid, Editorial Complutense, 2006, pp. 165-189.

Di Stefano, Giuseppe (ed.) (2010): Romancero. Edición, introducción y notas de Giusseppe Di Stefano, Madrid, Castalia.

Duran, Eulàlia (dir.) (1998): Repertori de manuscrits catalans (1474-1620). Volum 1. Barcelona: Arxiu Històric i Biblioteca de Catalunya. Direcció: Eulàlia Duran. Compilació a cura de M. del Mar Batlle, Eulàlia Miralles, Maria Toldrà, Joan Tres, Barcelona, Institut d'Estudis Catalans.

Fernández de Heredia, Joan (1955): Obras. Edición, prólogo y notas de Rafael Ferreres, Madrid, Espasa-Calpe.

Gornall, John, y Colin Smith (1985): "Góngora, Cervantes, and the Romancero: Some Interactions", The Modern Language Review, LXXX/2, pp. 351-361.

Labrador Herraiz, José J., Ralph A. DiFranco y Antonio López Budia (eds.) (2003): Cancionero sevillano de Lisboa. Poesías Varias de Diversos Authores em Castelhano (LN F.G. Cod. 3072). Edición de José J. Labrador Herraiz, Ralph A. DiFranco, Antonio López Budia. Prólogo de Begoña López Bueno, Sevilla, Universidad de Sevilla.

March, Ausiàs (1912): Les Obres d'Auzias March. Edició crítica per Amadeu Pagès, I, Barcelona, Institut d'Estudis Catalans.

Massó i Torrents, Jaume (1902): "Papers de Josep Tastu (1787-1849) existents avui en la 'Bibliothèque Mazarine' de París”, Revista de Bibliografia Catalana, II, pp. 140-155.

Massó i Torrents, Jaume (1917): "Les poesies d'en Joan Pujol, de Mataró", Butlletí de la Biblioteca de Catalunya, VII, pp. 120-123.

Massó i Torrents, Jaume (1932): Repertori de l'Antiga Literatura Catalana. La poesia. Vol. I, Barcelona, Editorial Alpha.

MCEM (2012): Duran, Eulàlia (dir.), y Maria Toldrà (coord.), MCEM (Base de dades de Manuscrits Catalans de l'Edat Moderna), Barcelona, Institut d'Estudis Catalans, <http:// mcem.iec.cat/> [fecha de consulta: 24/07/2012].

Molinier, Auguste (1898): "Supplément. 1898", Catalogue des manuscrits de la Bibliothèque Mazarine. Tome quatrième, París, Librairie Plon.

Pagès, Amédée (1888): "Notice sur la vie et les travaux de Joseph Tastu", Revue des Langues Romanes, XXXII, pp. 57-76 y 127-145. 
Pavia i Simó, Josep (1994): “Joan Pau Pujol. Biografia”, Joan Pau Pujol: la música d'una època, Barcelona, Patronat Municipal de Cultura de Mataró-Editorial Alta Fulla, pp. 77-106.

Piacentini, Giuliana (1990): "Una lectura de las glosas del Romance de Belerma", en Enrique Rodríguez Cepeda (ed.), Actas del Congreso Romancero-Cancionero UCLA (1984). Edición de Enrique Rodríguez Cepeda, con la colaboración especial y 'Bibliografía crítica' de Samuel G. Armistead, Madrid, José Porrúa Turanzas, I, pp. 153-164.

Piacentini, Giuliana, y Blanca Periñán (eds.) (2002): Glosas de romances viejos. Siglo XVI, Pisa, Edizioni ETS.

Pliegos-Madrid (1960): Pliegos poéticos góticos. Edición conmemorativa realizada bajo el patrocinio de la Dirección General de Archivos y Bibliotecas, IV, Madrid, Joyas Bibliográficas.

Pujol, Joan (1962): "Una carta literària”, Ausa, IV, pp. 192-194.

Pujol, Joan (1970): Obra poètica. A cura de Karl-Heinz Anton, Barcelona, Edicions 62.

Pujol, Joan (1971): Edición facsímile de la "Singular y admirable victoria que per la gracia de N. S. D. obtingue el Serenissim Senyor don Juan Daustria de la potentissima armada Turquesca. Composta per Joan Pujol Prevere de Mataro", Barcelona, Diputación Provincial de Barcelona-Talleres de la Escuela de Trabajo.

Riquer, Martín de (ed.) (2003): Chanson de Roland. Cantar de Roldán y el Roncesvalles navarro. Texto original, traducción, introducción y notas por Martín de Riquer, Barcelona, Quaderns Crema.

Rodríguez-Moñino, Antonio (1973): Manual bibliográfico de cancioneros y romanceros impresos durante el siglo XVI. Por Antonio Rodríguez-Moñino. Coordinado por Arthur L-F. Askins, II, Madrid, Castalia.

Rodríguez-Moñino, Antonio (1978): Manual bibliográfico de cancioneros y romanceros impresos durante el siglo XVII. Por Antonio Rodríguez-Moñino. Coordinado por Arthur L-F. Askins, II, Madrid, Castalia.

Rodríguez-Moñino, Antonio (1997): Nuevo diccionario bibliográfico de pliegos sueltos poéticos (siglo XVI). Edición corregida y actualizada por Arthur L-F. Askins y Víctor Infantes, Madrid, Castalia-Editora Regional de Extremadura.

Romeu i Figueras, Josep (1974): Poesia popular i literatura. Estudis i textos, Barcelona, Curial.

Romeu i Figueras, Josep (1999): Assaigs de literatura valenciana del Renaixement, Alacant, Universitat d'Alacant-Institut Interuniversitari de Filologia Valenciana.

Rouanet, Léo (1901): Coleccion de Autos, Farsas y Coloquios del siglo XVI, I, Barcelona-Madrid, L'Avenç-Libreria de M. Murillo.

Solervicens, Josep (1997): El diàleg renaixentista: Joan Lluís Vives, Cristòfor Despuig, Lluís Milà, Antoni Agustí, Barcelona, Publicacions de l'Abadia de Montserrat.

Tato, Cleofé (2010): "Una nueva y fragmentaria versión del romance 'Muerto yaze Durandarte' en una probatio calami”, Revista de Filología Española, XC/2, pp. 279-302.

Torres Amat, Félix (1836): Memorias para ayudar a formar un diccionario crítico de los escritores catalanes, y dar alguna idea de la antigua y moderna literatura de Cataluña, Barcelona, Imprenta de J. Verdaguer.

Vellvehí i Altamira, Jaume (1991): "Joan Pujol i la seva obra: estat de la qüestió", VII Sessió d'Estudis Mataronins (12 de maig de 1990). Comunicacions presentades, Mataró, Museu Arxiu de Santa Maria-Patronat Municipal de Cultura, pp. 73-83.

Vellvehí i Altamira, Jaume (1993): "Sobre les possibles variants de la glossa de Joan Pujol d'Als fats coman tot quan serà de mi d'Ausiàs March”, XI Sessió d'Estudis Mataronins (28 de novembre de 1992). Comunicacions presentades, Mataró, Museu Arxiu de Santa MariaPatronat Municipal de Cultura, pp. 105-111.

Fecha de recepción: 11 de noviembre de 2011

Fecha de aceptación: 17 de julio de 2012 